\title{
Characteristics of Selected Migrant Farmworkers in West Texas and Southern New Mexico
}

\author{
Jane E. Poss and Rebecca Pierce \\ Migrant Border Health Initiative \\ University of Texas at El Paso
}

\begin{abstract}
Resumen
Approximately 4.2 million migrant and seasonal farmworkers and their families work in the United States, and 1.6 million are classified as migrants. Migrant farmworkers are known to have more health problems than the general population, and they lack dependable access to health care services. Little is known about the status of farmworkers in the area surrounding El Paso, Texas. We report here the results of a survey of the demographic and health characteristics of 150 migrant farmworkers in West Texas and Southern New Mexico.

Aproximadamente 4.2 millones de trabajadores agrícolas emigrantes y temporales y sus familias trabajan en los Estados Unidos, y 1.6 millones son clasificados como trabajadores emigrantes. Se conoce que los trabajadores agrícolas emigrantes tienen más problemas de salud que la población en general, y ellos no tienen acceso confiable a servicios de cuidado de salud. Se sabe muy poco sobre el estatus de los trabajadores agrícolas en el área alrededor de El Paso, Texas. Aquí reportamos los resultados de un estudio demográfico y las características de salud de 150 trabajadores agrícolas emigrantes en el oeste de Texas y sur de Nuevo México.
\end{abstract}

(c) 2003 Californian Journal of Health Promotion. All rights reserved.

Keywords: migrant farm workers, agricultural workers, chronic disease, delivery of health care

While the exact number of farmworkers in the United States is not known, sources estimate that there are approximately 4.2 million migrant and seasonal farmworkers and their families living in every state of this nation, and, of these, about 1.6 million are classified as migrants (US Department of Health and Human Services, 1990). Migrant farmworkers have more health problems and suffer from infectious and chronic diseases more frequently than the general population, and they lack dependable access to health care services (Dever, 1991; Goldsmith, 1989; Rust, 1990; Slesinger, Christenson, \& Cautley, 1986; Wilk, 1986).

The Office of Migrant Health, Department of Health and Human Services bases its definition of migrant farmworker on the United States Public Health Services Act Section 329: A migrant is "an individual whose principal employment is in agriculture on a seasonal basis, who has been so employed within the last 24 months, and who establishes for the purpose of such employment a temporary abode". A seasonal worker is defined by the same criteria, but does not change residence.

Identification of the farmworker population is difficult because migrant workers often live in remote rural locations and, by definition, are peripatetic, moving within the United States as well as into and out of the United States on a seasonal basis. Some workers do not have required immigration and work papers and therefore avoid contact with government agencies and remain uncounted. Definitions of the population vary; some sources include nonmigrating seasonal workers or dependents traveling with migrating farmworkers. In addition, the political interests of the organization producing the estimates often affect the count (Sakala, 1987). 
The Census of Population and other governmental classification indices do not include migrant farmworkers in their occupational categories, and population-based surveys, such as the National Health Interview Survey, do not specifically identify migrant farmworkers (Martin, 1988; Slesinger, 1992). Only a limited number of studies of migrants have utilized random sampling methods that would provide a basis for estimating total numbers of farmworkers.

There are few national surveys that provide information about migrant and seasonal farmworkers. The National Agricultural Workers Survey (NAWS) includes workers other than migrant farmworkers, and no attempt is made to isolate data relative to migrants. Nonetheless, the findings of the study are helpful in understanding agricultural workers, many of whom are migrant farmworkers.

A recent NAWS revealed that $81 \%$ of the farm labor force was foreign born and, of these, 95\% were Mexican nationals (US Department of Labor, 2000). The average age of these workers was 31 , and $80 \%$ were male. About $84 \%$ spoke Spanish, and less than $5 \%$ of the Mexican-born farmworkers could read and speak English well. Over half (52\%) lacked work authorization. As Sakala (1987) observed, many growers prefer to employ undocumented immigrants because these workers are politically vulnerable, less likely to make demands, and willing to work hard for low wages.

In the NAWS, the median highest grade of schooling completed was sixth grade, with most completing this schooling in their country of origin. About $45 \%$ of farmworkers had children and, of those who were parents, half were not accompanied by their children. Three-fifths of the workers and their families lived below the poverty level.

Texas is the major sending state for migrant workers in the United States, and, for this and other reasons, calculating the size of the farmworker population in this state is difficult (Larson, 2000). Workers may spend part of the year in Texas working in agriculture and then migrate to other states during the planting and harvest season. According to the Migrant and Seasonal Farmworker Enumeration Profiles Study for Texas, there are 4,745 migrant farmworkers and family members in El Paso County (Larson, 2000).

Migrant farmworkers tend to travel in certain patterns referred to as "migratory streams". East coast stream workers may live in Florida and other Southeastern states during the winter months and travel north to "upstream" states generally over routes east of the Appalachian Mountains, although East coast workers travel to the Midwest as well. The Midwestern stream begins in Mexico and southern Texas and proceeds north to Michigan, Ohio, Indiana, Illinois, Iowa, Minnesota and other states. Some Midwestern stream migrants travel as far east as New York state. The West coast stream begins in Mexico, southern California and Texas. Some workers travel only within a single state while others migrate from Texas as far as the Pacific Northwest and back (Johnston, 1985).

There is considerable overlap between the migrant streams depending on the weather, crop conditions, and work opportunities. Other workers may travel within a relatively small geographic area, known as a restricted circuit. Some farmworkers in the El Paso / Cuidad Juarez area work only in the local region following the local chili, onion and cotton harvests.

Agriculture consistently ranks as one of the most hazardous occupations in the United States. According to the National Safety Council, agriculture had the highest rate of accidental deaths in 1993 with 35 deaths per 100,000 workers (National Safety Council, 1994). In addition to disabling farm injuries, which are most often caused by working with farm machinery, persons employed in the agricultural sector have higher than normal rates of pulmonary disease, dermatological diseases, certain cancers, acute and chronic chemical toxicity, noise-related hearing loss, and stressrelated mental illness, especially depression. 
Because most migrant farmworkers are employed in the agricultural sector, they are exposed to these health problems, but, in addition, they are subjected to other stressors including poverty and inadequate nutrition, a highly mobile lifestyle, poor living and working conditions, inadequate medical care, difficulty obtaining medical insurance and worker's compensation, and cultural and language barriers (Rothenberg, 1998).

Migrant farmworkers have exceptional health needs and yet they are poorly integrated into the health care system in the United States. Most studies demonstrate low overall rates of utilization of health care services and reveal that workers tend to seek treatment for acute problems rather than for chronic conditions or for health promotion and disease prevention services (Wilk, 1986). When primary care is not available, the emergency room is often used for treatment of non-emergent problems (Bechtel, Shepherd, \& Rogers, 1995). A recent study of oral health issues among 119 migrant workers living in Illinois revealed that $42 \%$ of subjects sought dental care only if they experienced pain, and $51 \%$ had not sought oral health care during the previous year (Lukes, 2002). Many subjects in Lukes' study experienced oral health problems including bleeding gums (50\%), swollen or tender gums (37\%), and tooth loss (49\%).

When the Migrant Health Act (Public Health Service Act, Sec. 310) was enacted in 1962, it authorized funds for public and private nonprofit organizations to establish health centers and train medical staff to deliver primary and supplemental health services to domestic agricultural migratory workers and their families (Johnston, 1985; Sakala, 1987). The Migrant Health Program, administered by the Department of Health and Human Services, is charged with delivering health care services to migrant and seasonal farmworkers. Estimates suggest that migrant health centers are able to serve less than $20 \%$ of the targeted population (Dever, 1991; Wilk, 1986).

Numerous reasons for migrant workers' low utilization rates of health services have been reported in the literature. The cost of health care can be overwhelming to a population that lives chronically below the poverty level, and many farmworkers are not aware of reduced fees available at some health centers. If migrants have received benefits in their home base state, they may not be eligible for Medicaid in the "upstream" state. If they do not have Medicaid, the process of applying for benefits can be overwhelming since application forms are lengthy and usually printed in English.

Because Medicaid is administered by the states, each state has its own eligibility requirements and farmworkers' income may be too high to qualify. In calculating income, caseworkers may use several high income weeks during the peak harvest season as the basis for estimating annual income. In survey of health care providers and migrant workers at clinics in four Eastern states, only $4 \%$ of respondents used Medicaid to pay for health care services (Rural Opportunities, 1988).

Health care workers are often inhospitable to the farmworker population resulting in their unwillingness to seek services for anything except emergency care. In a study of medical utilization patterns of migrant laborers in New York state, Chi (1985) surveyed a random sample of farmworkers. Over $40 \%$ of respondents indicated that they postponed seeking medical treatment when they had health problems. Reasons for the delay included insufficient time, expense of treatment, and, in about one-quarter of respondents, fear of medical practices, poor communication with nurses, or lack of faith in the medical profession.

Chi (1985) found that having Medicaid insurance increased the likelihood that migrant farmworkers visited physicians for both diagnostic and preventive health care. Fewer than $12 \%$ of respondents, however, were covered by Medicaid. In Wisconsin, Slesinger \& Cautley (1981) found that Medicaid recipients were more likely than others to have had dental and vision care. About $15 \%$ of their sample paid medical expenses with Medicaid. In another study, $17 \%$ of those surveyed used Medicaid or 
Title 19 funds to pay for health care (Slesinger \& Ofstead, 1993).

Other barriers to health care exist for migrant farmworkers. Health centers often are not open in the evening hours, and farmworkers are unwilling to lose wages to visit the center during the day. Many workers do not own motor vehicles and must depend on others for transportation. Language and cultural barriers can be formidable obstacles to seeking health care. Because of their migratory existence, farmworkers often are not aware of services available in the various locations where they work.

Obtaining care for acute occupational injuries may also be difficult for farmworkers. A study of 287 randomly selected farmworkers in North Carolina revealed that, of 17 workers who reported injuries sustained while working, 7 (41\%) did not receive treatment within 24 hours and $4(24 \%)$ never received medical care (Ciesielski, Hall, \& Sweeney, 1991). Reasons for not receiving medical attention included crew leader refusal and lack of transportation. Only $20 \%$ of workers received any compensation for lost work due to injury.

In their study of migrant workers in Colorado, Littlefield and Stout (1987) found that about $25 \%$ of respondents did not have a source of health care at their permanent residence (which was Texas for over half the sample). Of the total sample, $45 \%$ had not received any health care during the previous year. Over half of the sample used health services in Colorado at some time, with many using the migrant health clinic or community health center. In a Wisconsin study, $43 \%$ of the sample had not received medical care in the year before the interview. Of those workers who received care, $37 \%$ received that care in Wisconsin and over half of those went to the federally-funded migrant health clinic (Slesinger \& Cautley, 1981).

A literature search for studies examining the characteristics of migrant farmworkers in El Paso, TX revealed only one study, an investigation of working conditions in the region (Robson, Schneider, Marentes, \& Villanueva,
2001). The researchers studied 841 migrant workers from 38 work sites in El Paso and New Mexico. The mean age of workers was 51 year of, and the mean number of years worked in agriculture was 18.6. The authors found that while most workers had access to drinking water and toilet facilities at their work sites, about 31\% of sites lacked hand washing facilities. The study did not examine health-related characteristics of the sample.

\section{Method}

\section{Subjects}

After obtaining the approval of the Institutional Review Boards at the University of Texas at El Paso and Texas Tech University Health Sciences Center, the authors, both of whom are bilingual, conducted interviews in Spanish with a convenience sample of 150 subjects using a structured interview instrument developed for this study. Interviews, which lasted between 30 and 60 minutes, took place between January and December, 2001.

Subjects were recruited by initiating contact with several local agencies involved in migrant farm worker assistance programs and located in the El Paso and Hudspeth counties in Texas and Doña Ana County in New Mexico. The following agencies assisted in locating migrant farm workers: Texas Workforce Commission (TWC), the West Texas Council on Alcohol and Drug Abuse (WTCADA), the Socorro Independent School District Migrant Education Program (SISD-MEP), and the Sin Fronteras Organizing Project (SFOP).

Representatives from these agencies contacted area farmworker foremen and supervisors to obtain their permission to conduct interviews, and accompanied the interviewers to the fields where migrant and seasonal farmworkers were at work. Interviews were conducted in La Union and Anthony, New Mexico and Clint, Fabens, Tornillo and San Elizario, Texas with the interviewers often walking along side the migrant/seasonal farm workers as they harvested crops (principally onions and chilies) so that work would not be interrupted. The SISD-MEP recruiter assist by locating female migrant workers who were willing to participate in the 
study. These subjects were interviewed in their homes in Socorro, Texas. The Executive Director of the SFOP gave permission to conduct migrant farm worker interviews at the Centro de los Trabajadores Agricolas Fronterizos (CTAF), a shelter for migrant workers who do not have housing in the local area. The majority of the interviews $(71 \%)$ were conducted at this site.

\section{Instruments and Translation}

The statement of informed consent and the interview instrument were written in English at a fifth-grade reading level and were translated into Spanish by a qualified translator who is familiar with the Spanish used along the US/Mexico border area in El Paso County. The Spanish version was back-translated into English by a second qualified translator, and the results compared with the original English version. Modifications were made to the instruments with the assistance of the translators to ensure clarity in both versions. These procedures for establishing equivalency of dual language instruments follow the procedures established by Brislin, Lonner, \& Thorndike (1973) and Marín and Marín (1991).

The statement of informed consent was read to participants because many had completed minimal formal education. Participants were provided with a complete description of the study and its purpose. Participants gave verbal consent if they wished to participate in the study, and they were given a copy of the consent form. The interview instrument consisted of seven sections: Demographics, Health Status, Occupational Health, Mental Health, Dental Care, Nutrition, and Sources of Health Care Information and Health Services. We did not ask subjects about their citizenship or legal status.

\section{Results}

\section{Demographic Characteristics}

Data were analyzed using an Excel database. Demographic characteristics of the sample are summarized in Table 1. All participants in the survey were either currently employed in agriculture or had worked in agriculture during the previous harvest season. One hundred percent of the sample was of Mexican ancestry. The sample was composed of 132 (88\%) males, and the average age of the subjects was 48 . Most of the sample $(\mathrm{N}=104 ; 69 \%)$ was married, 33 $(22 \%)$ were single, and the remaining $9 \%$ were either divorced or widowed. The number of children per farmworker ranged from $0-16$, and $115(77 \%)$ had 5 or fewer children. The vast majority of subjects $(97 \%)$ worked directly in the fields, mainly in the chili and onion harvest. Most subjects $(\mathrm{N}=105 ; 70 \%)$ spoke no English and, of those who reported they spoke some English, only 5\% considered their command of the language to be good or excellent.

Table 1

Demographic Characteristics of the Sample $(\mathrm{N}=150)$

\begin{tabular}{|l|c|r|}
\hline \multicolumn{1}{|c|}{ Category } & Range & Mean \\
\hline Age & $18-74$ & 48 \\
\hline Number of children & $1-16$ & 4 \\
\hline Monthly income & $\$ 150-1500$ & $\$ 612$. \\
\hline Years in farm work & $1-60$ & 18 \\
\hline Years of education & $0-12$ & 5 \\
\hline
\end{tabular}

The place of birth for $93 \%$ of the sample was Mexico. Of those born in Mexico, the majority was born in the states of Chihuahua, Coahuila, and Durango. The sample was divided about evenly between those who considered their "home base" to be in the US (54\%) and those whose "home base" was Mexico (46\%). In terms of migratory status, 114 subjects $(76 \%)$ planned 
to move to other parts of the US in the near future to look for work.

Health Status. When asked to describe their general health, $76(51 \%)$ rated it "good" or "excellent", while $74(49 \%)$ rated their health "fair" or "poor". Subjects were asked if they had ever been diagnosed with specific chronic illnesses. Over $21 \%$ of the sample $(n=32)$ reported a diagnosis of type 2 diabetes, $37(25 \%)$ had hypertension, $18(12 \%)$ had chronic skin conditions, and $22(15 \%)$ had chronic arthritis. Thirty three subjects (22\%) purchased medications to treat these and other ailments in the US, $61(41 \%)$ went to Mexico to get medications, and 55 (37\%) bought medicines in both countries. Ninety seven (35\%) subjects smoked cigarettes, with the majority of those smoking one-half pack per day. No one in the sample used chewing tobacco.

Occupational Health. Questions were included in the survey about self-reported symptoms of pesticide exposure and work-related injuries. Over half $(57 \%)$ of the subjects believed they had suffered symptoms of pesticide exposure while working in agriculture. Symptoms reported included skin rash, eye irritation, nausea, diarrhea, breathing problems, headache and confusion. When asked if they could name symptoms of pesticide exposure, $84(56 \%)$ of the subjects were able to correctly identify at least one symptom. Twenty one percent of subjects reported having been injured at least once while working in agriculture.

Mental Health. Farmworkers in the study were asked if they felt generally emotionally healthy, and $130(87 \%)$ replied that they did. Fifty percent were able to correctly identify symptoms of mental health problems. Subjects were questioned if they had ever experienced specific mental health-related symptoms while engaged in farm work. Symptoms reported included sadness (37\%), depression (26\%), anxiety $(28 \%)$, and insomnia (24\%). Subjects reported having daily concerns with the following issues: working conditions (64\%), living conditions (47\%), financial problems (49\%), and family problems $(39 \%)$.

Dental Care. Only 15 (10\%) of subjects had ever received dental care while working in the US. The vast majority $(96 \%)$ reported that they would have to pay for any dental care received because they lacked insurance. When asked about self dental care, 93\% stated they brushed their teeth at least once a day. Eighty two (55\%) subjects had received some dental care in Mexico, and 68 (45\%) subjects had never received regular dental care.

Nutrition. Subjects' heights and weights were measured in order to calculate their Body Mass Index (BMI). The mean BMI was 28, which falls in the overweight category. The breakdown of the subjects' BMI is shown in Table 2.

Table 2

Distribution of BMI for Subjects $(\mathrm{N}=149)^{*}$

\begin{tabular}{|l|c|c|}
\hline \multicolumn{1}{|c|}{ BMI (kg/m $\mathbf{2})$} & Number & Percent \\
\hline Normal $(18.5-24.9)$ & 43 & 28.9 \\
\hline Overweight $(25.0-29.9)$ & 59 & 39.6 \\
\hline Obese I (30.0-34.9) & 38 & 25.5 \\
\hline Obese II (35.0-39.9) & 7 & 4.7 \\
\hline Obese III (40.0+) & 2 & 1.3 \\
\hline
\end{tabular}

*Source for BMI categories: National Heart, Lung and Blood Institute (www.caloriecontrol.org/bmi.html).

Subjects were asked what they generally ate for breakfast, lunch and dinner while working in agriculture. Most subjects ate a high fat diet that included few fruits and vegetables. Less than $36 \%$ ate one serving of vegetables on a daily basis, and about $48 \%$ ate at least one serving of 
fruit daily. The majority of the workers did not have access to cooking facilities and relied on fast food or vendors at agricultural work sites for their meals.

Sources of health care information and health services. Workers surveyed reported that, while working in the US, they received health information on a variety of topics: tuberculosis, sexually transmitted diseases, hepatitis, diabetes, nutrition, cancer, heat-related illnesses, and pesticide exposure. All workers who had received information believed the materials were helpful to them. Many workers spontaneously requested that health-related educational sessions be provided for them.

Study participants were asked to identify their primary strategy for seeking care when they were ill. Sixty two (41\%) reported they sought medical care in the US, $57(38 \%)$ received medical care in Mexico, 27 (18\%) engaged in self care activities and $6(4 \%)$ sought care from a naturalist or other healer. About $60 \%$ of the sample had used health care services in the US and, of those, $78 \%$ rated the care they received as excellent or good, while $22 \%$ rated it fair or poor. The method of payment used by those who had received health care is shown in Table 3.

Table 3

Method of Payment for Health Care Services $(\mathrm{N}=96)$

\begin{tabular}{|l|c|c|}
\hline \multicolumn{1}{|c|}{ Method of Payment } & Number & Percent \\
\hline Self pay & 55 & 57.3 \\
\hline Not charged for services & 16 & 16.7 \\
\hline Medicaid & 11 & 11.5 \\
\hline Employer & 5 & 5.2 \\
\hline Social service agency & 4 & 4.2 \\
\hline Medicare & 3 & 3.1 \\
\hline Family assisted & 1 & 1.0 \\
\hline Private insurance & 1 & 1.0 \\
\hline
\end{tabular}

\section{Discussion}

The subjects for this study were not selected randomly, therefore, the sample may not be characteristic of migrant workers in the region. The primary language of these subjects, English capabilities, and mean number of years of schooling were similar to those of the national sample interviewed for the NAWS. The average age of the subjects $(\mathrm{N}=48)$ in our study and the mean number of years employed in farm work $(\mathrm{N}=18)$ were similar to the findings of the other study conducted in the El Paso region (Robson, Schneider, Marentes, \& Villanueva, 2001), but were considerably higher than that of subjects in the NAWS. The reasons for this difference are unclear, however younger workers may be more willing and able to migrate to other parts of the US. Older workers may suffer from more health problems, be physically weaker than younger workers, and be less able to take on the challenges of long migrations. These older workers may constitute one of the primary sources of labor in our region.

The self-reported prevalence of type 2 diabetes among study subjects was $21 \%$ which is much higher than the $10 \%$ prevalence for Mexican American adults in the United States (Harris, et al., 1998) or the $16.5 \%$ prevalence of diabetes Mexican American adults in El Paso County (El Paso Diabetes Association, 2000). The reasons for this are not clear, although the subjects' mean age of 48 may contribute to this higher prevalence.

A large number of subjects in our study reported symptoms that could be associated with compromised mental health, including depression, sadness, anxiety, and insomnia. A majority was concerned about finances, living 
and working conditions, and family problems. Certainly, living apart from family and community and the vicissitudes of the migratory life style may contribute to mental health problems.

A majority of subjects was knowledgably about symptoms of pesticide exposure, and over half reported experiencing these symptoms during their years of work in agriculture. About one fifth of the sample reported being injured while working in agriculture. Subjects' nutritional status was suboptimal; they ate high fat diets with few fruits and vegetables, and their mean BMI was in the overweight range. This degree of overweight and obesity is especially significant in a population that is engaged in hard physical labor, and suggests that subjects were eating a diet very high in calories.
The fact that subjects sought health care on both sides of the US/Mexico border reflects their binational existence. Similar to the results of national surveys, such as the NAWS, few workers had health insurance and a small percentage had Medicare or Medicaid. Most subjects paid for their health care out of pocket.

This survey represents the initial phase of a research agenda designed to examine the health characteristics and needs of migrant farmworkers in the El Paso region. Future research will examine the housing characteristics of migrant workers, their utilization of health care services, their health education needs, and their use of herbal and home remedies. Because El Paso is one of the major points of entry for migrant workers into the US, there remains much work to be done to learn more about the health care characteristics and needs of this population.

\section{References}

Bechtel, G. A., Shepherd, M. A., \& Rogers, P. W. (1995). Family, culture, and health practices among migrant farmworkers. Journal of Community Health Nursing, 12, 15-22.

Brislin, R. W., Lonner, W. J., \& Thorndike, E. M. (1973). Cross-cultural research methods. New York: Wiley.

Chi, P. S. K. (1985). Medical utilization patterns of migrant farm workers in Wayne County, New York. Public Health Reports, 100, 480-490.

Ciesielski, S. D., Hall, S. P., \& Sweeney, M. (1991). Occupational injuries among North Carolina migrant farmworkers. American Journal of Public Health, 81, 926-927.

Dever, G. E. A. (1991). Migrant health status: Profile of a population with complex health problems. Austin, TX: National Migrant Resource Program.

El Paso Diabetes Association (2000). Diabetes awareness and education in the community survey: Summary Report. El Paso, TX: Author.

Harris, M. I., Flesgal, K. M., Cowie, C. C., Eberhardt, M. S., Goldstein, D. E., Little, R. R., Wiedmeyer, H. M., \& Byrd-Holt, D. D. (1998). Prevalence of diabetes, impaired fasting glucose, and impaired glucose tolerance in U.S. adults: The third national health and nutrition examination survey (NHANES), 1988-94. Diabetes Care, 21, 518-524.

Goldsmith, M. F. (1989). As farmworkers help keep America healthy, illness may be their harvest. JAMA, 261, 3207-3213.

Johnston, H. L. (1985). Health for the nation's harvesters: A history of the migrant health program in its economic and social setting. Farmington Hills, MI: National Migrant Worker Council.

Larson, A.C. (2000). Migrant and seasonal farmworker enumeration profiles study: Texas. Washington, DC: Migrant Health Program. Bureau of Primary Health Care. Health Resources and Services Administration.

Littlefield, C., \& Stout, C. L. (1987). A survey of Colorado's migrant farmworkers: Access to health care. International Migrant Review, 21, 688-707.

Lukes, S. (2002) Oral health issues among migrant farmworkers. Journal of Dental Hygiene, 76, 134-140.

Marín, G., \& Marín, B. V. (1991). Research with Hispanic populations. Newbury Park, CA: Sage Publications. 
Martin, P. L. (1988). Harvest of confusion: Migrant workers in U. S. agriculture. Boulder, CO: Westview Press.

National Safety Council. (1994). Accident facts, 1994. Itasca, IL.

Robson, M., Schneider, D., Marentes, C., \& Villanueva, E. (2001). Field conditions for agricultural workers in the El Paso, Texas region. New Solutions: A Journal of Environmental and Occupational Health Policy, 11, 141-148.

Rothenberg, D. (1998). With these hands: The hidden world of migrant farm workers today. New York: Harcourt Brace.

Rural Opportunities, I. (1988). A study of farmworker health care availability and utilization. Rochester, NY: Author.

Rust, G. S. (1990). Health status of migrant farmworkers: A literature review and commentary. American Journal of Public Health, 80, 1213-1217.

Sakala, C. (1987). Migrant and seasonal farmworkers in the United States: A review of health hazards, status, and policy. International Migration Review, 21, 659-687.

Slesinger, D. P. (1992). Health status and needs of migrant farm workers in the United States: A literature review. Journal of Rural Health, 8, 227-234.

Slesinger, D. P., \& Cautley, E. (1981). Medical utilization patterns of Hispanic migrant farmworkers in Wisconsin. Public Health Reports, 96, 255-263.

Slesinger, D. P., Christenson, B. A., \& Cautley, E. (1986). Health and mortality of migrant farm children. Social Science and Medicine, 23, 65-74.

Slesinger, D. P., \& Ofstead, C. (1993). Economic and health needs of Wisconsin migrant farm workers. Journal of Rural Health, 9, 138-148.

U.S. Department of Health and Human Services, Public Health Service, Health Resources and Services Administration (1990). An atlas of state profiles which estimate number of migrant and seasonal farm workers and members of their families. Rockville, MD: U.S. Department of Health and Human Services.

U.S. Department of Labor (2000). Findings from the national agricultural worker survey (NAWS) 19971998: A demographic and employment profile of United State Farmworkers. Research Report No. 8. Washington: U.S. Department of Labor.

Wilk, V. A. (1986). The occupational health of migrant and seasonal farmworkers in the United States (2nd ed.). Washington, DC: Farmworker Justice Fund, Inc.

\section{Acknowledgements}

This project was supported in part by funds from the Office of Rural Health Policy (ORHP) Special Projects, Health Resources and Services Administration (HRSA), Department of Health and Human Services (DHHS) under grant number \#1-DIA-RH-00007-01 entitled "Migrant Border Health Initiative". The information or content and conclusions are those of the author and should not be construed as the official position or policy of, nor should any endorsements be inferred by the ORHP, BHPr, DHHS or the U.S. Government. 


\author{
$\underline{\text { Author Information }}$ \\ Jane E. Poss, DNSc, ANP,C \\ Professor and Director, Family Nurse Practitioner Program \\ Co-Principal Investigator, Migrant Border Health Initiative \\ University of Texas at El Paso \\ 1101 North Campbell \\ El Paso, TX 79902 \\ Ph. 915-747-7259 \\ E-Mail: jeposs@utep.edu \\ Rebecca Pierce, MS, MT \\ Project Director, Migrant Border Health Initiative \\ University of Texas at El Paso \\ 1101 North Campbell \\ El Paso, TX 79902 \\ Ph. 915-747-8301
}

